\title{
Spread of Composite Pollutants in Shallow Waters of the Niger Delta
}

\author{
*1 ABBEY, T M ; ${ }^{1}$ ANYALEBECHI, O; ${ }^{3}$ AKONYE, L A \\ Environmental Research Group, Faculty of Science, University of Port Harcourt, Nigeria. \\ ${ }^{1}$ Department of Physics, ${ }^{3}$ Department of Plant Science and Biotechnology,
}

\begin{abstract}
Experimental survey has been advanced on the effects of composite pollutants spread in shallow waters of the Niger Delta, using the Trans-Amadi creek as a case study. The analysis, which involves the identification of the nature of pollutants by the absorption photo spectrometer method and the Aitken Lagrangian interpolation model, shows that the contaminated water body, whose contaminants resulted from both human and industrial wastes consist of $\mathrm{K}, \mathrm{Mg}, \mathrm{Mn}, \mathrm{Fe}, \mathrm{Zn}$ and $\mathrm{SO}_{4}^{2-}$ pollutants. The amount per litre of these elements in the sampled water were found to be higher than the United Nation recommended standards. The analysis shows that the spread follow a trend of the form: $C(y, \tau) \operatorname{Co} \sum_{n \rightarrow 0}^{1}\left(\alpha_{o} y^{o}\right) \sum_{m \rightarrow 0}^{2} \beta_{o} \tau_{o} ; C_{o}$ is the initial quantity deposited at the point $\mathrm{y}=0$. The overall analysis shows that $\mathrm{K}, \mathrm{Mg}, \mathrm{Mn}$ and $\mathrm{SO}_{4}^{2-}$ were most predominant in the spread. @JASEM
\end{abstract}

Creeks and rivers are major source of livelihood to the inhabitants of the geographical area called the Niger Delta, located between latitude $4^{0}, 30^{\prime}-6^{0}, 30^{\prime} \mathrm{N}$ and longitude $4^{0}, 15-8^{0} 30^{\prime} \mathrm{E}$ and covering a land mass of 70,000 square kilometers. (Abbey et al 2003) This region is said to be the richest zone of the Nigeria Nation state with respect to its natural resources with large oil and gas deposits. As a result of industrial activities which include, oil and gas exploration and exploitation and coupled with the rapid population growth, the region is threatened by the effect of environmental hazard and degradations. The bulk of the waste generated by this fast growing population and industries has always found their ways into the surrounding rivers and creeks (Anyalebechi, 2005). For instance Ibielele (1993) and SPDC (1993) environmental impact assessment reports cited in Moffat et al (1995) show that the concentration of dissolved hydrocarbons in waste water from refineries and oil exporting terminals in the creeks of the Niger Delta between the year 1980 to 1983 were found to be on the increase from $53.9 \mathrm{mg} / \mathrm{litre}$ to $62.9 \mathrm{mg} / \mathrm{litre}$ in and around the Oloma creek near the Bonny oil terminal. The result shows that although the Oloma community is a little farther from the operating terminal but the run-off is transported to Oloma shore and creek through the creek linkage by a connective mechanism. In another development, refineries in and around the Niger Delta is estimated to produce over $90 \%$ of the hazardrous sludge, which is subsequently deposited in neighbouring swamps (Moffat et al 1995). In addition to these, there is the predominant behaviour of the inhabitants of these areas who generally form the habit of defecating at and dumping their waste on the river bank, thereby increasing the fececal count or coliform count of the river.

Efforts made to abate pollution, particularly water pollution in creeks and rivers by various agencies have not yielded the much, needed results. The risk posed by material pollutants in rivers are better analyzed base on the information gather on the amount or concentration of the pollutant, its toxicity and its exposure of the human receptor. Hence, pollutant concentration has become important tool in simulating the exposure-assessment processes. As a result of the import of rivers and creeks to its inhabitants and the effect the various form of pollution might have on the rivers as well as the biotic life in the creeks, several researchers in the literature have put in great efforts to study pollutants transport mechanism in rivers and more importantly in swallow waters. Amongst these are the works of Wnek and Pochtmen (1972), Cleary and Adrian (1993), Hunt (1976), Rust (1982), French - McCay and Deborah (1982), Martin (1994), Shieh et al (1996), Dias et al (1996) Abbey et al (1997) Garcia Navarro (2000), Rimkus (2001) and Forstner (2004) to mention but a few. None of these have considered the situation in which the pollutants consist of different form of materials which is usually the case in actual practices (Walter et al, 2001).To this end, considering the complex biological, chemical and fluvial processes of the rivers, a better understanding of pollutants transport will definitely lead to a better solutions of the control mechanism of the associated environmental problems. This present study presents experimental analysis on the transport of composite pollutants in creeks and rivers of the Niger Delta region. The analysis is limited to the transport and 
spread in swallow waters. The area under survey is the Trans Amadi Creek in Rivers State, Nigeria which housed several industries, ranging from oil serving to oil producing along side several petrochemical industries. The creek also play host to one of the popular abattoirs in Port Harcourt metropolis. All these emptied their waste onto the Trans Amadi Creek, through some interconnected channels and drainages. The following format is adopted in the presentation of the study, section 1 handles the introduction while sections 2 and 3 discussed the material and method as well as the result respectively. The Atlkin Lagragian technique is employed in the analysis of the experimental data.

\section{MATERIALS AND METHODS}

Choice of survey Area: As noted in the introduction, the Niger Delta region, according to studies and report in the literature, is facing the problem of environmental degradation which is occasioned by the activities of various chemical and petrochemical industries. The situation becomes worst as the area is noticing in-flock of people due to its economic viabilities and activities Moffat et al (1995) cited the result of an extensive study conducted on water quality for this area and show that over $85 \%$ of the water samples contained coliform counts of $40 \%$ and above. This result which is above the recommend World Health Organization (WHO) standard indicates a fecal contamination of the water. The expanding population and industries in this area in recent times have over whelmed the efficacy of the above result. Amidst poor waste management practices in stagnant areas, water has becomes septic for human excrement, household and industrial waste dumping. Industrial effluents and residential wastes are discharged into the drains which finally emptied themselves into the water body.

The Trans-Amadi creek is therefore selected for the purpose of the experimental surveys. The selection is based on the fact that the area, being an industrial area, housed one of the biggest slaughter, chemical and petrochemical industries. Secondly the creek also runs through some major communities which are heavily populated. All these communities emptied their wastes into the drains, which are transported to the creek. Simply put, the creek acts as a repository of all waste generated with in the industrial area.

Sample Collection: Water samples were collected from the Trans - Amadi creek in Ogonigba, Rivers State, Niger Delta. The samples were collected at every mapped out point of $0,25,50,75,100,125$ and
150 metres along the creek in both length, width and depth. At each of these points, two different samples were taken, one at the top and the other at the bottom of the creek. Divers were employed in the collection of the samples. The samples were collected, using sterile reagent bottles to avoid interference of impurities other than those in the water body, at a six (6) hourly intervals. To obtain the samples at the bottom, a diver had to go into the water body with a sterile reagent bottle, which opens as he gets to the bottom and then obtains the water sample at the desired point. The samples were collected over a period of twelve months so as to eliminate errors in the analysis.

Chemical Analysis: The water Samples were labeled and subjected to a chemical analysis using the absorption spectroscopy method for the identification of species and their concentration in the water. The choice of the instruments is based on the efficacy of the spectrophotometer, which consist of prisms and grating monochromators, that permits a continuos choice of wavelength. The absorption photospectrometer has the potential of measuring and analyzing samples in the ultraviolet, visible and infrared regions of the electromagnetic spectrum. To this end, the monochromators disperse radiation into their component wave lengths. The filters in the spectrometer limit radiation by absorbing certain portions of the frequency spectrum. The most common type of filters consist of coloured glass or a dye suspended in a gelatin and sandwiched between glass plates. The spectrophotometer employed in the analysis of our samples cousist of coloured glass. This type of spectrometer has the advantage of greater thermal stability. It measures the transmittance or absorbance of the solution. It has a radiation detector or transducer that converts the radiant energy to a measurable signal. The signals are then picked up by the indicator and the corresponding values read and recorded. The result is thereafter interpreted analytically. Several water samples obtained at each of the various positions were similarly analyzed and the average of the measurement from the spectrometer taken.

\section{RESULTS}

The chemical analysis reveals the presence of the following elements $\mathrm{K}, \mathrm{Mg}, \mathrm{Mn}, \mathrm{Fe}, \mathrm{Zn}$ and $\mathrm{SO}_{4}^{2-}$ in the water samples. The quantity in mass of each element present in the samples is indicated below on Table 1 and 2. 
Table 1: Pollutant concentration at various positions (x) toward the shore

\begin{tabular}{cccccc}
\hline Positions (in & \multicolumn{5}{c}{ Concentration in $\mathrm{mg} /$ litre } \\
metres) X & $\mathrm{K}$ & $\mathrm{Mg}$ & $\mathrm{Mn}$ & $\mathrm{Fe}$ & $\mathrm{Zn}$ \\
0.00 & 115.50 & 198.00 & 0.130 & 1.19 & 0.450 \\
25.00 & 54.25 & 73.94 & 0.083 & 1.32 & 0.260 \\
50.00 & 21.01 & 27.24 & 0.060 & 1.37 & 0.120 \\
75.00 & 7.20 & 10.31 & 0.047 & 1.39 & 0.079 \\
100.00 & 5.31 & 7.12 & 0.040 & 1.41 & 0.040 \\
72.00 & 2.14 & 4.43 & 0.011 & 1.47 & 0.025 \\
150.00 & 1.46 & 2.01 & 0.001 & 1.52 & 0.020 \\
\hline
\end{tabular}

Table 2: Pollutant concentration at various tine ( $t$ )

\begin{tabular}{rcccc}
\hline $\begin{array}{l}\text { Time }(\mathrm{t}) \text { of } \\
\text { measurement } \\
\text { (in hours) }\end{array}$ & $\mathrm{K}$ & $\mathrm{Mg}$ & $\mathrm{Fe}$ & $\mathrm{SO}_{4}^{2-}$ \\
0.00 & 115.5 & 198.00 & 0.12 & 612.0 \\
6.00 & 44.4 & 132.92 & 0.19 & 508.0 \\
12.00 & 40.4 & 129.26 & 0.23. & 124.0 \\
18.00 & 46.5 & 139.73 & 0.24 & 121.0 \\
\hline
\end{tabular}

Table 1 shows the average result of the chemical analysis for sample collected at different position (x) along the creek toward the shore for a period of twelve months while Table (2) presents the average result for the various samples collected at different time $(\mathrm{t})$. The samples were collected at 6 hourly intervals from 6.00 am to $12 \mathrm{mid}$ night each day and for over a period of twelve months.

Trend Analysis: The Interpolation Model: To have an over view of the pattern of spread of the contaminants and to be able to predict what the situation would be in the future assuming the rate of deposition of the contaminant remain the same, a regression analysis is carried out on the data presented on Tables (1) and (2) for the various contaminants obtained from the chemical analysis. The Aitken Lagrangian interpolating method is adopted in the analysis of the result. The method following Jain et al, (2004) can be given as

$I_{0}, i \ldots n(x)=\frac{1}{x_{n}-x_{n-1}}\left|\begin{array}{ll}\left(I_{o, 1, \ldots n-1}(x)\right) & \left(x_{n-1}-x\right) \\ \left(I_{o, 1, \ldots n-2, n}(x)\right) & \left(x_{n}-x\right)\end{array}\right|$

Further analysis reduces equation (1) to the form

$\mathrm{I}_{\mathrm{j}}(\mathrm{x})=\frac{\mathrm{W}(\mathrm{x})}{\left(\mathrm{x}-\mathrm{x}_{\mathrm{j}}\right) \mathrm{W}^{\prime}\left(\mathrm{x}_{\mathrm{j}}\right)}$

where,

$\mathrm{W}(\mathrm{x})=\left(\mathrm{x}-\mathrm{x}_{0}\right)\left(\mathrm{x}-\mathrm{x}_{1}\right)\left(\mathrm{x}-\mathrm{x}_{2}\right) \ldots\left(\mathrm{x}-\mathrm{x}_{\mathrm{j}-1}\right)\left(\mathrm{x}-\mathrm{x}_{\mathrm{j}+1}\right) \ldots\left(\mathrm{x}-\mathrm{x}_{\mathrm{n}}\right)=\prod_{J=o}^{n}\left(x-x_{j}\right)$

and

$\mathrm{W}^{\prime}(\mathrm{x})=\left(\mathrm{x}_{\mathrm{j}}-\mathrm{x}_{0}\right)\left(\mathrm{x}_{\mathrm{j}}-\mathrm{x}_{1}\right)\left(\mathrm{x}_{\mathrm{j}}-\mathrm{x}_{2}\right) \ldots\left(\mathrm{x}_{\mathrm{j}}-\mathrm{x}_{\mathrm{j}-1}\right)\left(\mathrm{x}_{\mathrm{j}}-\mathrm{x}_{1+1}\right) \ldots\left(\mathrm{x}_{\mathrm{j}}-\mathrm{x}_{\mathrm{n}}\right)=\prod_{k=o}^{n}\left(x_{j}-x_{k}\right)$

with $\mathrm{j}=0,1,2,3 \ldots n$ and $j \neq k$ 
Hence the interpolating function describing the spread of the pollutants in the shallow waters becomes;

$\mathrm{F}(\mathrm{x})=\sum_{j=0}^{n} I_{j}(x) \mathrm{P}\left(\mathrm{x}_{\mathrm{j}}\right)$

where $n$ represent the number of entries, $x_{j}$ is the $j$ th position of the $\mathrm{x}$ - entry, $\mathrm{P}\left(\mathrm{x}_{\mathrm{j}}\right)$ is the measured or experimental value corresponding to a given $x_{j}$-value and $F(x)$ is the expected interpolating function that correctly fit the experimental data. In our case $\mathrm{F}(\mathrm{x})$ represent $\mathrm{C}(\mathrm{x})$ or $\mathrm{C}(\tau)$. Therefore, applying the above interpolation model to the data presented on tables (1) and (2), the interpolating function describing the trend of the pollutants in the shallow water become

$$
C\left(y, \tau_{l}\right)=A_{o i} \sum_{n=o}^{3} \propto_{n} y^{n} \sum_{k=0}^{2} \beta_{k} \tau^{r i}
$$

Where, $\alpha_{\mathrm{o}}=\beta_{\mathrm{o}}=1.0$ and $\alpha_{\mathrm{j}}$ and $\beta_{\mathrm{j}}, \mathrm{j}=1,2,3$, are as summarized on Table 3 below

Table 3

\begin{tabular}{|c|c|c|c|c|c|c|}
\hline \multirow{2}{*}{$\begin{array}{c}\text { Name of canter } \\
\text { pollutant }\end{array}$} & \multirow{2}{*}{$\begin{array}{c}\text { Initial quantity } \\
\text { deposited at } \mathrm{x}= \\
0, \mathrm{t}=0 \text { Ao } \\
\text { (mg/lits). }\end{array}$} & \multicolumn{3}{|c|}{$\alpha_{j}$} & \multicolumn{2}{|c|}{$\beta_{\mathrm{j}}$} \\
\hline & & $\alpha_{1}$ & $\alpha_{2}$ & $\alpha_{3}$ & $\beta_{1}$ & $\beta_{2}$ \\
\hline Potassium (K) & 115.50 & -1.352 & +0.631 & -0.097 & -0.200 & +0.111 \\
\hline Magnesium (Mg) & 198.00 & -1.471 & +0.723 & -0.114 & -0.083 & +.053 \\
\hline Manganese (Mn) & 0.13 & -0.908 & +0.458 & -0.089 & - & - \\
\hline Iron $(\mathrm{Fe})$ & 1.19 & +0.269 & -0.147 & +0.30 & 40.316 & -0.105 \\
\hline Zinc (Zn) & 0.45 & -1.152 & +0.489 & -0.071 & - & - \\
\hline Sulphate $\left(\mathrm{SO}_{4}{ }^{2-}\right)$ & 612.00 & - & - & - & -2.294 & +0.396 \\
\hline
\end{tabular}

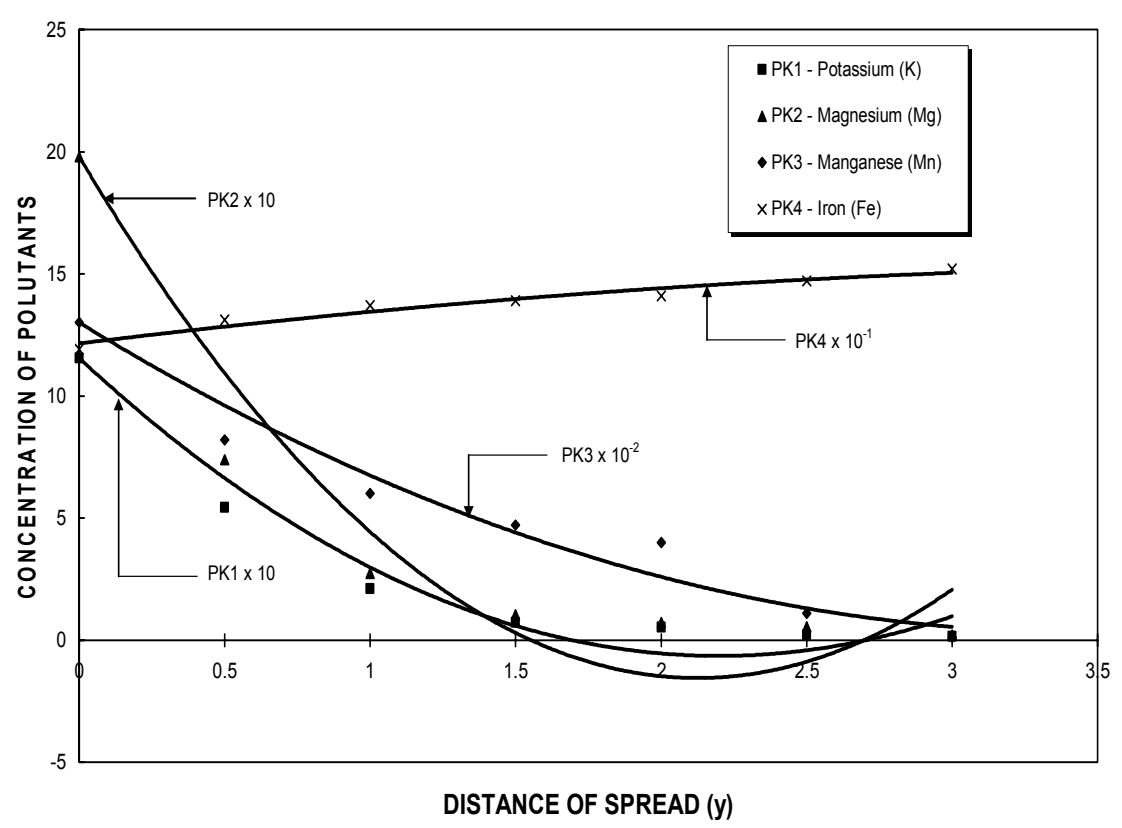

Fig. 1: Quantity of pollutants per distance of spread.

\section{DISCUSSION}

Pollutants spread in the shallow waters particularly of the Niger Delta have caused several problems and controversies in region where they occur. Sometimes the pollutant spread can elicit among others gross biological damage, physiological effects on the biotic life which include plants and animal. It can also 
results in severe economic loss (Susu et al, 1997). These effects are usually caused by the physical nature of the contaminants as well as the chemical components of the pollutants. To access the effects of the pollutant on the communities in and round the creek particularly when the pollutant source is complex, that is when the source consist of several forms of toxi elements, analytical curves are drawn based on the results of the interpolations. These curves are presented in figures (1) - (3) for the various constituents elements found in the pollutant. Figure 1 show the trend of the chemical contaminant of the elements:- Potassium (K), Magnesium (Mg), Manganise $(\mathrm{Mn})$, Zinc $(\mathrm{Zn})$ and Iron $(\mathrm{Fe})$ respectively, for the different positions y along the creek and toward the shore. On the other hand figure (2) indicate the trend of the chemical pollutants concentration with time $(\tau)$ for Sulphate $\left(\mathrm{SO}_{4}^{2-}\right)$; Magnesium (Mg); Potassium (k) and Iron (Fe) respectively. Further analysis shows that Sulphate $\left(\mathrm{SO}_{4}^{2-}\right)$, Magnesium $(\mathrm{Mg})$ and Potassium (k) substances dominated the spread of the pollutants. That is the analysis reveals that these substances were more noticeable in all the samples collected and analyzed. The above observations indicate that the spread of the pollutants down the creek can not only be explained by physical processes but also by the rate of chemical decentigration of the element. According to April and Parker (2002), the time rate of chemical disintegration is proportional to the rate of physical transport of the pollutant down the river course and the rate of disappearance of the substances. This is easily explained by the relation. $\mathrm{R}$ $=\frac{\partial c}{\partial \tau}+u \frac{\partial c}{\partial x}$ where $u$ is the drift velocity of the pollutant and $\mathrm{R}$ is the rate of its disappearance either by bio-degradation or evaporation or sedimentation or both processes. In a situation where the source of deposition is constant over a given time frame then the equation above simplifies to a steady state (time invariant) form, thus
$\mathrm{R}=\mathrm{u} \frac{\mathrm{dc}}{\mathrm{dx}}$, this means that the change in concentration of a chemical as a function of river distance is proportional to its rate of disappearance. This value is easily determined by chemical process depending on chemical speciation (Johnson et al., 1989). In our case figure (3) illustrates the profiles of $\mathrm{R}$ with distances along the river course for the various chemical pollutants. For instance, from our result, the increase in concentration with time and distance observed in the case of Iron $(\mathrm{Fe})$ can be explained in terms of complexation and redox reaction.

That is, in a slightly acidic to alkaline condition, $\mathrm{Fe}^{3+}$ precipitates as $\mathrm{Fe}(\mathrm{OH})_{2}$ (ferric hydroxide) where as $\mathrm{Fe}^{2+}$ is very soluble and does not retain other metals. The reduction of $\mathrm{Fe}^{3+}$ to $\mathrm{Fe}^{2+}$ releases not only $\mathrm{Fe}^{2+}$ to the water but any other pollutants that were adsorbed to the ferric hydroxide surface (Johnson et al, 1989). It is this $\mathrm{Fe}^{2+}$ found at the bottom that is transported faster down the river course which occasionally returned to the top of the river by turbulence process and then oxidizes back to $\mathrm{Fe}^{3+}$. This complexation process has effect on the transport of metal ions: in rivers.

One way by which complexes may stabilize themselves is by acid-base reaction. Thus the formation of $\mathrm{Fe}\left(\mathrm{H}_{2} \mathrm{O}\right)_{3}{ }^{(\mathrm{s})}$ shows that stabilization is attained through precipitation reactions. It is this precipitate that produces the binding surfaces for other pollutants and biological contaminants like coliform. The complex formed by $\mathrm{Fe}$ can also attain stability by redox reaction; $\mathrm{Fe}\left(\mathrm{H}_{2} \mathrm{O}\right)_{6}{ }^{3+} \quad \mathrm{Fe}(\mathrm{OH})_{3}$ $+3 \mathrm{H}_{2} \mathrm{O}+3 \mathrm{H}^{+}+\mathrm{e}$, it is this inter change (the equilibrium) conversion between ferrous and ferric, occasioned by ferrous oxidation to ferric and subsequent ferric reduction to ferrous that accounts for the observed increased in trend in its concentration of iron in the pollutant as they are being transport toward the shore. 


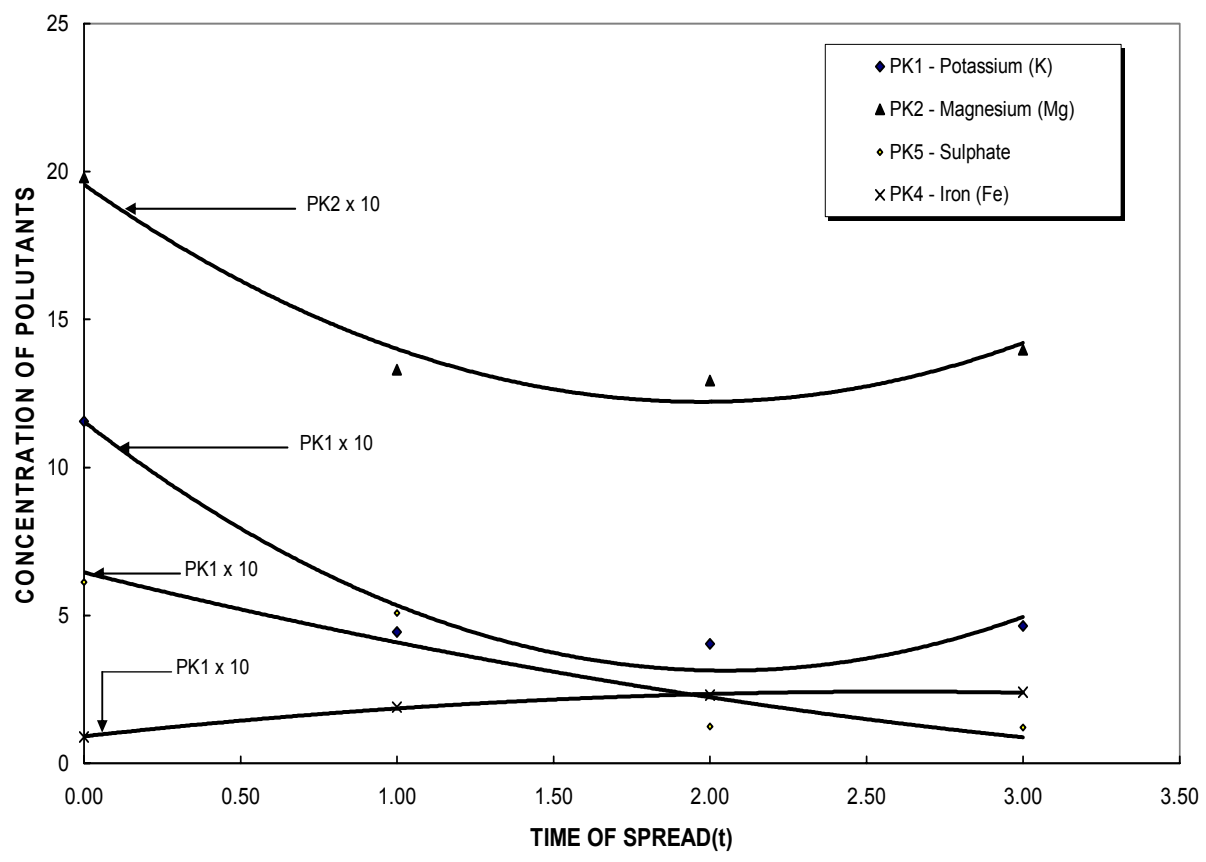

Fig. 2: Pollutants concentration profiles with time of spread.

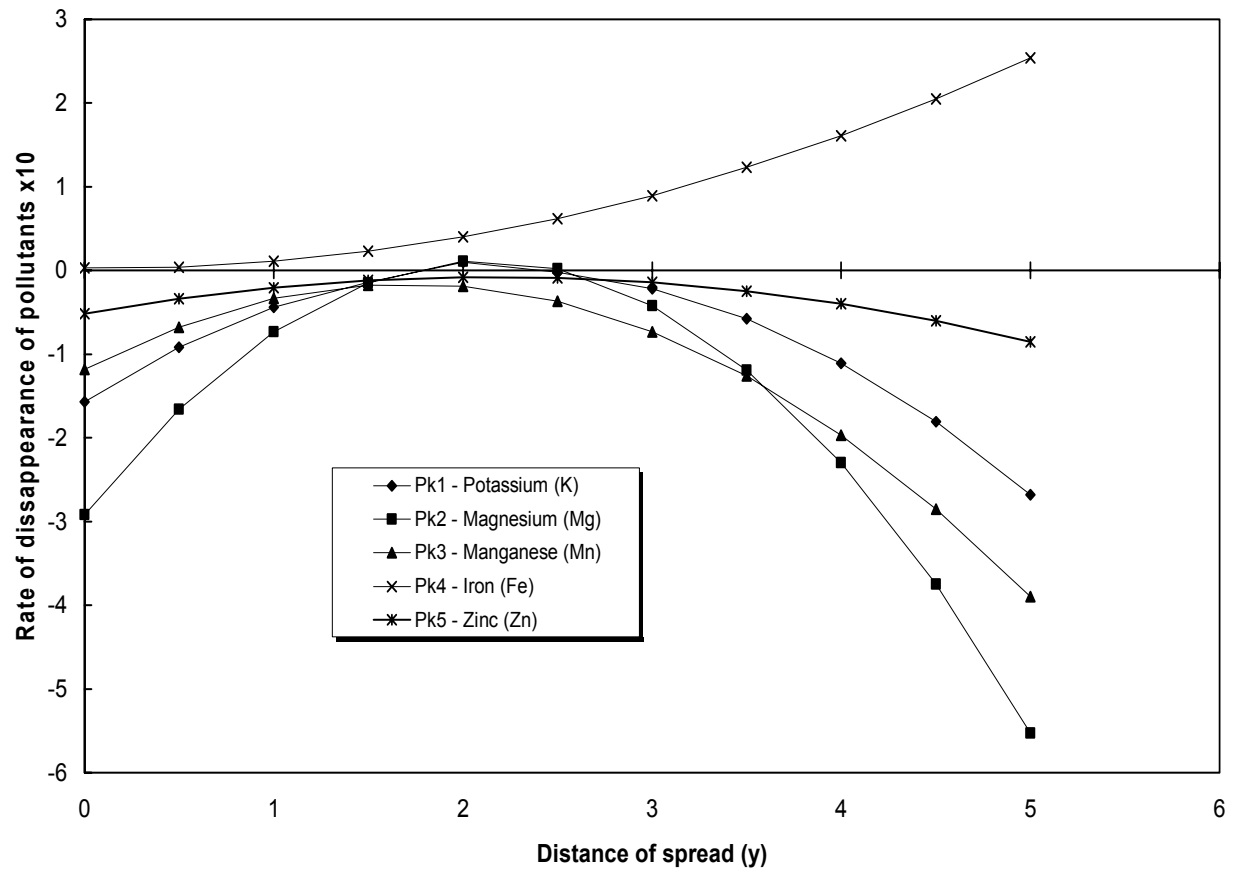

Fig. 3: Profiles of pollutant rate of disintegration with distance of spread. 
Conversely, the concentration profile of zinc $(\mathrm{Zn})$ whose oxides is amphoteric shows a disappearance as the distance increases. $\mathrm{SO}_{4}^{2-}$ also exhibits a similar trend. While $\mathrm{Zn}$ which is a transition metal and has a decrease in ionic radius with increasing nuclear charge resulting from its $3 \mathrm{~d}^{10} \mathrm{~S}^{2}$ structure is observed to exhibits a negative trend. Its decay as the trend shows is partly as a result of the fact that its oxide is slightly soluble in water thus

$$
\mathrm{ZnO}+2 \mathrm{OH}^{-}=\left(\mathrm{H}_{2} \mathrm{O} \mathrm{Zn}\right) \mathrm{HO}_{4}{ }^{2-}
$$

Therefore, its spread is the partly controlled by physical processes.

From the above discussion, it is obvious that the flow and spread of composite pollutants in rivers is governed by complex physical and chemical processes. These play vital role in remediation of contaminated river and preparation for emergency management plan to curp the spread and distribution of water borne disease in and around the coastal environments.

\section{REFERENCES}

Abbey T.M., Amakiri J.O. and Bestman A.R. (1997); "Effect of Pollutant Oscillations on oil Spread on the Sea"; Int. J. Energy Research 21, 655.

Anyalebechi O. (2005), The Flow of Multicomponent Pollutants in Rivers and Creek of the Niger Delta". M.Sc-Thesis, University of Port Harcourt, (un-publish).

April A.C. and. Parker J.K (2002); "Stream Pollutant Remediation"; A Freshman Engineering Design Project, Found at Coalition Alabama, USA.

Cleary R.W and Adrian D. (1972) "New Analytical Solution for Dye Diffusion Equation", J. Environment Engr., 99, E3.

Dias, J.M. Lopes J.F. and Dekeyser I. (1996); "Numerical Modeling of Tidal Fluxes and Passive Pollutant Concentration", Ria de Averro Portugal Trans. Ecology and Envir. 9, 1743.
Forstner W. (2004); "Sediment Dynamics and Pollutant Mobility in River- An Interdisciplinary Approach", Lakes and Reservoirs Research Mgt $9(1), 25$.

French - McCay D.P. (1982), "Oil Spill Impact Modelling:- Development and Validation", J. Envir. Toxicology and Chemistry, 23(10), 2441 $-56$.

Garcia - Navarro, P. Brufau P.; Ghilardi P., Natale I. and Savi F. (2000); " ID - Mathematics Modeling of Debris Flow"; J. Hydraulic Research 38 (6).

Jain, M.K. Iyengar S.R.K and Jain R.K. (2004); Numerical Methods for Scientific and Engineering Computation; New Age Int. Publishers, New Delhi, $4^{\text {th }}$ Edition. Pp. 218-327.

Johnson, R. H. Palmer C.D. and Fish W. (1989) "Subsurface Chemical Process - Transport", EPA, 62514, 89/019.

Martin H. (1994), "Incipient Motion and Particle Transport in gravel-bed Stream", Osu Valley Library, ID4330 1995D - M38.

Moffat M. and Linden O. (1995), "Perception and Reality; Assessing Priorities for Sustainable Development in the Nigeria Delta", Roy. Swedish Acad. Sci, 24(7).

Rust B.R. (1982), "Sedimentation in fluvial and Lacustrine environments"- Hydrobiologia (Historical Archiwe), Springer Pubs. Vol. 91-92 Noi, pp 59-70.

Shieh, C.L. Jan C.D. and Tsai Y.F. (1996), “A numerical Simulation of Debris Flow and its Application", Natural Hazard, 13, 39-54.

Susu, A.A. Abowei M.F.N. and Onyeme J.O. (1997) OIL Spills in the Marine Environment; CJC Press, Yaba - Lagos, pp 1-421.

Wnek N. J. and Fochtman E.G. (1972), Mathematical model for Fate of Pollutants in near Shore Water," J. Environment Science and Technology, 6. 